\title{
Innovation in Response to Climate Change
}

\author{
David Zilberman, Leslie Lipper, Nancy McCarthy, and Ben Gordon
}

\begin{abstract}
Climate change impacts on agriculture are varied over space and time. The effects are heterogeneous and highly uncertain. Innovation in agriculture is clearly an important response for effective and equitable adaptation and mitigation - and we need to rethink how to promote innovation to address the heterogeneity and uncertainty of climate change impacts. In moving towards climate smart agricultural (CSA) systems in developing and developed countries, innovation will be key. For CSA we will need greater resilience in agricultural systems and also greater efficiency of resource use for both adaptation and mitigation. Technological innovation will need to play a key role - but its not enough. Managerial and institutional innovations are likely to be even more important in dealing with the heterogeneous and uncertain impacts of climate change. Innovation can complement other forms of adaptation to climate change to form CSA practices. In particular innovation can enhance technology adoption, may prevent or facilitate migration of production/population, enhance trade $\&$ aid, and increase efficiency of insurance $\&$ feasibility of inventories. We discuss their main features and the nature of innovation needed to align these actions with a CSA strategy.
\end{abstract}

\section{Introduction}

The evolution of agriculture in the future will be shaped by its response to climate change. Farmers need to adapt their practices to accommodate climatic conditions, and agricultural activities will need to be modified to reduce greenhouse-gas (GHG)

\footnotetext{
D. Zilberman $(\bowtie) \bullet B$. Gordon

Department of Agriculture and Resource Economics, University of California Berkeley,

Berkeley, CA, USA

e-mail: zilber11@berkeley.edu; benjamingordon@berkeley.edu

L. Lipper

ISPC-CGIAR, Rome, Italy

e-mail: leslie.lipper@fao.org

N. McCarthy

Lead Analytics Inc., Washington, DC, USA

e-mail: nmccarthy@leadanalyticsinc.com
} 
emissions. But climate change is only one of the major forces that will change the future of agriculture. Others include population growth and increases in income as well as changes in human capital, knowledge, and infrastructure. Much of the change in agriculture will stem from new innovations, both in terms of technologies and institutions.

This paper aims to provide the background and analyze some of the challenges associated with the development and introduction of new innovations in agriculture and food systems in response to climate change. The analysis will emphasize the role of innovations in CSA. The first section will provide an overview of the impact of climate change and possible mechanisms in response to it. The next section will identify the major categories of innovation associated with CSA. We distinguish between technological, managerial, and institutional innovations and between micro (farm level) vs. macro (farm-system) innovations. This will be followed by a discussion of the barriers to introduction faced by these innovations, and a conclusion.

\section{The Impact of Climate Change on Agriculture and the Implications}

The research on climate change has identified several avenues that will affect agriculture. They include (1) rising temperatures around the world that lead to migration of climate from regions closer to the tropics to regions closer to the poles, (2) rising sea levels, (3) increased snowmelt and change in the volume and timing of water use for irrigation, and (4) increased probability of extreme events. We will next analyze the implications of each of these events and what they imply for the evolution of agricultural systems focusing on innovations, which are a crucial component for adaptation to climate change (Stern 2006).

\subsection{Rising Temperatures and Migrating Weather}

Depending on the range of mitigation actions taken in the next decades, we can expect that climate change will lead to increased temperatures throughout the world by $1-3{ }^{\circ} \mathrm{C}$, which is equivalent to a shift of $300-500 \mathrm{~km}$ of weather patterns away from the equator and towards the poles. Similarly, temperature variability in regions at higher altitudes will also increase (Ohmura 2012). While climate change may have negative overall impact on agricultural production, the distributional impacts are much more substantial than the aggregate affect. Thus, for instance, some warm agricultural areas in Texas, Oklahoma, Mexico, and Western Africa will become unviable for crop production. While at the same time, regions in Russia, Canada, and even the Arctic will become suitable for agricultural production. Innovations to respond to changes in temperature may involve adopting new crops and varieties in 
some areas, to migration away from regions unviable for agricultural production in others, or investment in infrastructure and other activities in new regions. The effect of weather migration will not be limited to plants, but rather felt across multiple species. For example, temperature serves as an important barrier to prevent pest infestations and while insects and other pests can move in response to changing conditions, trees are stationary. Pest migration can endanger viable tree-based economies and will require monitoring and interventions (Porter et al. 1991). The people displaced because of these trends may not be the ones that are able to take advantage of new opportunities presented by climate change. Development of new technologies and other economic activities to facilitate adaptation to climatic changes and amelioration of painful displacement will be valuable. Innovations to adapt to migration of weather will vary across location reflecting spatial heterogeneity. In some areas, new solutions will be required to address movement of pests as well as to modify crop varieties to adjust to changing weather conditions. In other areas, entirely new crops may need to be introduced. Finally, in some regions mechanisms may need to be introduced to facilitate out migration of people. The design and implementation of these solutions is challenged due to uncertainty about magnitude and timing of change.

\subsection{Rising Sea Levels}

Sea level rise (SLR) may lead to loss of high value agricultural land as well as important infrastructure that is crucial for exporting and importing food in many regions throughout the world. An estimated $10 \%$ of the world's population lives in coastal zones (i.e. at less than $10 \mathrm{~m}$ altitude), with wide variation in share of population by country, representing 14\% of global GDP (McGranahan et al. 2007). Most notably, close to half of Vietnam, Bangladesh, and Egypt's populations live in these zones, while China and India, with a far smaller portion of overall population, contain over 200 million people living in these zones. The population impacted by SLR will vary significantly by actual rise in sea level - from 56 million people (1.28\% of world population) with a $1-\mathrm{m}$ rise to 245 million $(5.57 \%$ ) with a $5-\mathrm{m}$ rise (Dasgupta et al. 2009). Also, large tracts of prime agricultural land will be threatened by rising sea levels especially in tropical regions (Kurukulasuriya and Rosenthal 2013). Given heterogeneity across location, it is important to develop location specific solutions. In areas especially vulnerable to SLR, transformational innovation may be required rather than incremental approaches in order to spur adaptation and protect vulnerable populations (Kates et al. 2012). In few areas, vulnerable coastal regions may be saved by investment in protective infrastructure (e.g. dikes, dams), but in many cases vulnerable areas will need to be abandoned causing problems of displacement. In some areas, there may be opportunities to adopt different types of agricultural production, but these will require innovation. 


\subsection{Increased Snowmelt and Timing of Irrigation}

In addition to changes in precipitation patterns, increased temperatures will increase snowmelt, decreasing the possibility of using water stored in snow accumulated during the wet season to be available for irrigation during the dry season. Furthermore, the likelihood of flooding may increase. Given the relative importance of irrigated agriculture during dry seasons in many parts of the world, this change may have significant impact on food supply, unless some remedial measures are taken. These solutions are dependent on the conditions at each location. Solutions may include investment in new forms of water inventories and storage, for example dams for flood control and storage as well as diversion of water to underground reservoirs. These changes may also prompt changes in crop timing and selection to adjust to water availability. Furthermore, changes in water availability may also affect availability of hydroelectric power for irrigation, which will also affect agricultural supply (Xie et al. 2015). Thus climate change will prompt re-arrangement and new management of agricultural water supplies (Grafton et al. 2013; Chartzoulakis and Bertaki 2015; Basist er al. forthcoming). The substitution of snow as water storage will require significant investment under conditions of uncertainty and require innovative approaches to financial, institutional, and physical structures applying and extending the option-value approach of Dixit and Pindyck (1994).

\subsection{Increased Probability of Extreme Events}

In addition to the changes in average temperature as well as water availability, climate change is likely to shift the climatic distribution that will increase the probability of extreme events, such as heatwaves, heavy rainfall, storms and coastal flooding. Furthermore, climate change is a gradual process. While average conditions may be changing gradually, there may be increased variability of climatic conditions (Fischer and Schär 2009). There is already evidence of such changes and they require a higher degree of resilience of farmers to fast changing conditions. This requires both innovative efforts in terms of new technologies and management practices, as well as capacity to adopt these technologies and thus enhance resilience.

Furthermore, there is a risk of climate change triggering a tipping point that will lead to abrupt and irreversible changes that increase in severity with rising temperature (IPCC 2014; Barnosky et al. 2012). Such very low probability catastrophic events may include, for example, drastic rise in temperature (of $6{ }^{\circ} \mathrm{C}$ and beyond) because of sudden release of methane gas resulting from the loss of permafrost (Lenton et al. 2008). Such extreme events may devastate agriculture throughout much of the world. Nevertheless there is a need for continued research to develop agricultural production and storage systems suitable for more extreme climate conditions as well as institutions for emergency responses that include movement of people and other living creatures and relocation of resources. 


\subsection{Discussion}

As emphasized above, the nature of innovative responses to climate change impacts need to adapt to two characteristics of these impacts. The first is heterogeneity. Different regions are affected differentially by climate change: for some desert or low-lying coastal region climate change may be devastating, while for other cold region, climate change may be perceived as "climate improvement". These differences in impacts, as well as differences in gains and losses from engagement in mitigation activities, may contribute to the diverse responses and willingness to participate and contribute to coordinated efforts to avert or slow climate change. Weitzman (2009) studies the economic significance of catastrophic climate change and argues that regardless of the differential impacts of likely climate change scenarios on various regions, humanity as a whole needs to take action to prevent some low probability catastrophic outcomes.

The second factor that affects engaging in action addressing the climate change challenges is uncertainty. The timing, magnitudes and locations of different impacts of climate change are not known with certainty. At the same time, there is a wide body of literature that suggests that farmers and other agricultural actors behave in a manner consistent with risk aversion. Sandmo (1971) suggests, in a static framework, that risk aversion reduces the magnitude of actions taken by risk averse enterprises as the risks they face increase. The real option approach of Dixit and Pindyck (1994) argues, within a dynamic setup, that higher uncertainty about future outcomes will lead to a delay of actions. Thus, the uncertainty surrounding the impacts of climate change tend to delay and reduce the magnitude of activities aimed to adapt to and mitigate it. Uncertainty about possible impacts of climate change also increases the need for further research (Dixit and Pindyck 1994) to reduce the uncertainties surrounding climate change.

Heterogeneity and uncertainty will thus increase the difficulty of identifying the full range of responses to climate change from observable data, especially at the present when some of the impacts of climate change (e.g., migration of warm weather toward the pole and a significant rising sea level, triggering of tipping points leading to irreversible changes) are more likely to occur in the longer run2050 and beyond. Others, for example, that increase the likelihood of extreme events, like flood and droughts, might have already started to occur and are more likely in the near future.

The investment in innovative activities to address the challenges of climate change will evolve over time as knowledge accumulates. The innovative approach must consider new technological and institutional options but also the changes in behavioral responses to climate change and related solutions over time.

We can learn from the responses thus far on some activities, the capacity to adapt to climate change in the future, and the factors that affect responses. The empirical case studies in these chapters cover lessons that have analyzed responses to climate change thus far and their implications for innovation, including technology adoption and adaptation, insurance schemes, and diversification of land and labor, and to a lesser extent internal migration. While these case studies cover a subset of 
adaptation options for which there is solid empirical evidence in developing country contexts, there is a broader range of adaptation activities that we will also cover, including external migration, use of trade and aid policies, and physical inventories.

\section{Innovations for Climate Smart Agriculture}

There are many ways to categorize innovations (Sunding and Zilberman 2001). Economic growth theory distinguishes among technologies depending on their impact on inputs and outputs. For example, distinctions can be made between capital saving, labor saving, quality improving, and risk reducing innovations. Another way of distinguishing innovations is according to their form, e.g. technological, managerial, and institutional innovations. Technological innovations are embodied in new machinery, and can be further divided into mechanical (e.g. tractors), biological (e.g. seeds), and chemical (e.g. fertilizers) innovations. Managerial innovations are not embodied in physical capital, but rather are described by better practices such as Integrated Pest Management, improved pruning techniques, and crop rotation. Institutional innovations may include new organizational forms (e.g. cooperatives) and arrangements for trading (e.g. future markets and contract farming). Because of the heterogeneity and randomness of climate change impacts, there are several types of innovation that will be especially valuable, and the following section outlines many of these innovations. Below we present and analyze the innovations that are likely to be required to adapt to climate change. We classify them in three categories: technological innovations, managerial innovations and institutional innovations. The technological and managerial innovations are divided into micro-farm level innovations and macro-farm system innovations. All the institutional innovations we consider are at the macro level.

\subsection{Technological Innovations}

\subsubsection{Micro, Farm-Level Approaches}

Resilient crops and livestock Because of rising temperatures and increased variability, development of new crop varieties and livestock breeds that can tolerate these changes will be very important. Due to the frequency of change, it will be important to detect change and develop genetic material that can adapt to this change relatively fast.

Pest control The migration of pests may prompt the need to develop new pest management techniques, which are both environmentally friendly, cost-effective, easy to use, and efficacious. A diverse approach utilizing biological, mechanical, and 
chemical control, in concert with genetic approaches, will be needed. An on going effort to identify emerging pest problem will need to guide the development these pest control innovations.

Input use efficiency enhancing technologies Frequently, there is a significant gap between the level of applied inputs and the amount utilized by the crop. For example, with flood irrigation, input use efficiency may be $50 \%$, but with technologies like drip irrigation, efficiency may increase to $90 \%$. Frequently the residue (i.e. the input not taken up by the crop) is a source of externalities. Khanna and Zilberman (1997) suggest that adoption of input use efficiency enhancing technologies tend to increase yield, save input, and reduce pollution. Better application technologies may reduce water, fertilizer, and chemicals while reducing the side effect associated with their use. The notion of input use efficiency enhancing technologies applies to crops and even livestock. Some crop varieties may increase output while the change in feeding regimes for livestock may decrease greenhouse gas emissions.

On-farm storage Parfitt et al. (2010) suggest that there is significant post-harvest loss on the farm and much of it occurs among subsistence farmers in developing countries that lack basic storage capacity. Innovative on-farm storage infrastructure can help address yield losses brought on by increased temperature as well as increased frequency of shocks. The challenge is to design systems that are affordable, easy to install and operate, and reliable. The design of the system must address heterogeneity in bioclimatic conditions.

Higher yield and longer shelf life Crop varieties, as well as livestock, that increase yield per area tend to reduce agricultural footprint and the effort required to compensate for production loss due to climate change. Longer shelf life would decrease transportation costs, storage costs, and, especially, waste associated with agricultural distribution. Shelf life enhancement is important in the context of climate change because increased temperatures increase the likelihood of spoilage.

Sustainable Land Management (SLM) Frequently, agricultural practices in developing countries lead to reduced soil quality. Extreme weather associated with climate change may worsen this problem unless improved agronomic practices are introduced. SLM practices aim to increase yield without degrading soil and water resources. In addition, they aim to sequester carbon. There are already several SLM practices such as organic fertilization, minimum soil disturbance, and incorporation of residues, terraces, water harvesting and conservation, and agroforestry (Branca et al. 2013), but there are many opportunities for developing new SLM practices and refining existing ones to accommodate spatial and climatic variability.

\subsubsection{Farm System Approaches}

Low-cost flood protection and water storage facilities Because of the concern of rising water level, and the resulting instability due to floods, innovation that reduces the cost of protection against rising water levels and floods will be a priority. In assessing 
such investments, it is important to consider the benefit of avoided conflict due to reduced climate migration.

Weather information distribution technologies There is significant evidence that availability of weather information, including its implications on irrigation (evapotranspiration losses), enable farmers to modify their irrigation and pest control strategies which lead to significant increases in yield and saving of water and other inputs (Parker and Zilberman 1996). Reliable weather information will be especially important during periods of heightened climate change during which farmers face greater uncertainty of weather patterns. But information about weather systems requires both weather stations as well as delivery systems that provide useful and reliable information across many users. This system must be affordable and fit the needs and capacity of poor farmers.

Improved mitigation Reducing GHGs is a key to effective adaptation to climate change in the long run, and an important CSA goal and thus it includes innovation and adoption of cultural practices, crop varieties, management practices, and institutions that will accelerate mitigation. Already, the transition to no- or low-tillage practices has been considered a major source of carbon sequestration, and adoption of higher yield varieties and conservation technologies that reduce the land, atmospheric, and fossil fuel footprint of agriculture is another important mitigation strategy (Lal 2011; McCarthy et al. 2012).

\subsection{Managerial Innovations}

\subsubsection{Micro, Farm-Level Approaches}

The differences between technological and managerial innovations are not clear cut. New machinery or input require innovative management practice to be effective and adopted. Here we will emphasize innovation that mostly emphasize improve management - but may also involve use of new technologies.

Input use efficiency management techniques The efficiency of water use or chemical input can be significantly increased through the adoption of information intensive management practices that optimize the timing and quantities of application of inputs. Precision technologies vary variable input application over space and time based improved monitoring of field and weather conditions. Dobermann et al. (2004) suggest that precision farming may save input and/or increase yield and that both mechanisms for monitoring spatial or other sources of variability and methods to utilize this information have a large potential for further improvement. Development of precision techniques for resource poor developing countries is a special challenge as they may be the major beneficiary from these techniques.

Integrated Pest Management (IPM) The likely increases in pest pressure because of climate change may require new technical solutions but also increase effectiveness 
of pest management in terms of detection and coordination of pest control activities. IPM emphasizes measurement of pest pressure and integration of alternative approaches (cultural practices, chemical, genetic modification and biological) to optimize the net benefits of treatment, taking into account pest dynamic and environmental side effects. The adoption of IPM is constrained by the cost of monitoring pests and difficulty of tailor-made IPM approaches specific to bioclimatic conditions (Waterfield and Zilberman 2012). The effectiveness of responses to climate change will benefit from the development of affordable and easy to implement IPM strategies.

Land use and on-farm management practices Changes in both the mean and variability of climatic conditions accompanied by changes in technologies and economic conditions will require improved management tools used to facilitate the selection of crop types and crop varieties, allocation of land among crops, and selection and implementation of production practices. The improvement of quality of data, computation capabilities and communication will provide opportunities for introducing new management tools that are affordable and accessible even to small farmers in developing countries.

\subsubsection{Farm System Approaches}

Local collective action for improved input use and management Management practices like IPM, SLM and improved input use efficiency require a knowledge base that is shared by many farmers. For example, both IPM and improved water use efficiency rely on weather information that may be collected by regional weather stations. Developing strategies to address crop diseases as well as controlling buildup of resistance to pest control will require collective action. Effective land use management should take into account externalities among crops and other production activities within a region. Therefore, development of regional institutions for collaboration that will allow for the provision of public goods and capturing economies of scale among small producers will be of high value. Poteete, Janssen, and Ostrom (2010) provide multiple forms of institutions to address various collective action challenges in the development context, but different situations may require different solutions and there are many opportunities for innovative institutional designs to address emerging climate change challenges.

Insurance Products The decreased stability of weather due to climate change raises the value of risk management strategies. For example, Mendelsohn (2006) suggests that crop insurance can be a good strategy to cope with increased risk. Golden et al. (2007) suggest that using weather derivatives and similar financial instruments can be an effective mechanism to address climate change related risk. The story of Joseph in the Bible illustrates the role of inventory as mitigating weather variability; similarly, there is a large literature on the economics of storage management in agriculture (Williams and Wright 2005) that applies to increased weather instability. 
The implementation of insurance as an adaptation mechanism is quite challenging. First, risks associated with climate change are difficult to quantity - risks are dynamic, rather than static, and the parameters of key variables change over time and cannot be predicted reliably (Patt et al. 2009). Furthermore, Millner et al. (2010) suggest that some impacts of climate change cannot be captured well by a standard probability distribution, which makes actuarial computation even more challenging. Second, insurance may affect other adaptation strategies. It may lead to a moral hazard by reducing precautionary activities, while other adaptation strategies may reduce the need for insurance. Thus risk and adaptation strategies must be designed simultaneously (Tol 2009). Third, implementation of insurance may require good monitoring of behavior to overcome adverse selection. The design of mechanisms to adverse selection is especially challenging when distributions of risks are evolving or partially unknown. Finally, agricultural insurance programs have served as rent seeking mechanisms (transferring income) indicating that their efficiency has been questionable (Schmitz 2010; Krueger 1990). Thus, the development of insurance strategies to address climate change must proceed with caution.

Resilient supply chain management Design of appropriate supply chains is essential to enhance effective adoption ( $\mathrm{Lu}$ et al. 2015). Agriculture in developing countries is going through a food system revolution characterized by the introduction of new rationalized supply chains that enable better storage and allow for product differentiation and link farmers in developing countries with super markets (Reardon and Timmer 2012). This modern supply chain led to the adoption of many innovative practices and a substantial effort must exist to enhance supply chains further to allow for coping with the effects of climate change.

\subsection{Institutional Innovations}

Institutional innovations occur at the macro, farm system level. We can distinguish between two types of institutional innovations: (1) Institutions that will enable innovation processes. Some of these institutions that are part of CSA innovations themselves are discussed in this section. Institutional innovations that address the limitations of the existing systems are discussed in next section on 'Overcoming Barriers to Innovation in the Era of Climate Change'. (2) Institutions that will allow implementing other elements of adaptation strategies besides innovation and adoption.

\subsubsection{Innovations as Part of CSA Programs}

"Climate Smart" extension programs Innovations are mostly concepts that present new ways of doing things within a context. To be implemented, innovations must be developed, upscaled, and then tested at the implementation level. A program of 
marketing and education is then needed to bring an innovation to practitioners. Different countries have their own innovation systems, which are adapted to different types of innovations and contexts (Nelson 1993). The implementation of CSA may require innovative design of networks that will extend the technology from the scientists to the practitioners and this extension effort should include not only the public extension service, but also private firms, cooperatives, and NGOs.

Integrated Pest Management at relevant ecosystem scale Pest control activities generate externalities, especially given the small scale of farms and the movement of pests. These externalities may be positive, for instance through pollination, or negative, for instance through the build-up of resistance. There are some activities that require the full spatial coordination among farmers, such as pest eradication plans (Waterfield and Zilberman 2012). The introduction of CSA pest management programs may require innovative efforts to identify and monitor their possible externalities and develop mechanisms to control them.

Land use regulations and management at ecosystem scale Agricultural production have significant environmental externalities, including chemical contamination of bodies of water and soil erosion, as well as damage to ecosystems and wildlife. The introduction of CSA activities without considering and addressing their potential side effects may lead to counter-productive outcomes. Therefore, innovative efforts are required to design systems of education and regulation to design and implement systems of regulation and implementation that will monitor the externalities of CSA and control them.

\subsubsection{Institutions for Enhancing Various Adaptation Strategies}

Trade regulations International trade results from differences in relative advantage between regions and is a risk sharing mechanism. Climatic changes and shifts in weather patterns, may result in crop production patterns that will lead to changes in trade. For example, Aker (2012) finds that increases in trade ameliorate the impact of drought in West Africa. A region with a warming climate may switch from growing wheat to corn, export the corn, and import wheat. Changes in trade patterns resulting from climate change may have significant distributional implications. Innovative frameworks that are able to identify new trade opportunities, their implications, and barriers to its implementation will be of importance. The capacity to utilize trade in response to climate change depends on infrastructure (e.g. availability of transportation and processing facilities) as well as international trade policies and institutions (Zilberman et al. 2012). New innovative frameworks can identify, for example, new infrastructure requirements and how to implement them and institutional arrangements that will provide an enabling environment for new trade opportunities.

Aid distribution mechanisms While trade is an exchange between two parties, aid is a transfer from one party to another. Even still, aid can play an important role as 
a mechanism to address risk associated with climate change. Like trade, the capacity of aid to address climate change depends on the availability of efficient transportation as well as accurate detection and response systems (Donaldson 2010). Both aid and trade could serve as substitutes to migration as a response to climate change. Research and development may lead to innovations that enable trade or to mechanisms that facilitate provision of aid in times of crisis while maintaining overall social welfare. Innovative approaches that reduce the cost of implementation and increase the effectiveness of aid mechanisms is especially important given financial constraints on such efforts.

Movement of water resources (management and conflict resolution) Climate change may drastically change precipitation patterns, as well as lead to significant melting of snow packs, and thus lead to changes in water availability over space and time, water movement and storage patterns. These changes will occur both within and between countries. It will raise issues of property rights that have to be sought and solved before they lead to conflicts. Furthermore, the institutions that currently own and distribute water will lose capacity, and some of them will get into severe financial troubles, as they would not be able to meet their obligations. At the same time, there will be a need to design and develop new water facilities and water distribution organizations that will be able to address the new reality.

Addressing these challenges require significant institutional innovations. There will be a need to develop insurance mechanisms for water districts and other water suppliers against the hydrological risks faced, as well as the resulting financial losses. As the knowledge about the changes in water supply and storage patterns emerge, there will be a need to rethink water infrastructure and supply. Designing water systems is a lengthy process and an early start may provide significant edge. The work of Xie and Zilberman (2016) shows that the investment in water project capacity is affected both by changes in water availability as well as the investment in water technology and thus regional planning of water systems is needed prior to the investment in water system modification.

One of the most challenging aspects of water resource management is the assignment of water rights. Traditional water rights systems, established during periods of water abundance and under colonial arrangements, can be an obstacle to efficient development of water resources (Schoengold and Zilberman 2007), and water right reform is essential for improvement to allocation. Legal and policy research that lead to innovative water right reform will be an important step in designing and implementing strategies to address water supply implications of climate change.

Insurance regulations Risk and uncertainty are the most challenging aspects of climate change. New designs of institutions to address these two facets are a major challenge. It is especially important to develop mechanisms that ensure farmers have insurance against extreme events. Much of the literature on crop insurance argues that it serves frequently as a subsidy rather than insurance per se, and farmers tend to undersubscribe to insurance schemes that are self-supporting. Furthermore, subsidized insurance may lead to engaging in risky and environmentally damaging behavior (see survey by Smith and Goodwin 2013). There are new forms of 
index-based agricultural insurance, but thus far, the quality of their performance has been questionable and there remains a significant need to redesign them (BinswangerMkhize 2012). With new sources of information and improved communication technologies, the continued redesign of various forms of insurance is a major challenge for interdisciplinary research and practitioners alike.

Social safety nets A higher frequency of extreme events and loss of livelihood due to changing weather may cause farmers to loss their main sources of income, and in many cases food for subsistence. Society will need to design innovative approaches to sustain individuals and communities that experience significant loss as a result of climate change. These approaches must enable them to survive through tough transitional periods while also providing the foundation for re-engaging in the economy. The design of safety net mechanisms may consist of emergency intervention, relocation, insurance arrangements, credit and financial products, and job training. These mechanisms need to be able to adjust to varying conditions and to recognize the limited capacity of the poor to utilize such assistance and insurance while also having rapid response times in order to be effective (Dercon 2002).

Incentives for farmer-level adoption The most important factor that affects adoption of new technologies is incentives. There is growing research to introduce innovative policies that will provide farmers the incentives to utilize new technologies, engage in preventive practices to reduce the risks of climate change, and adopt resilient new varieties and activities most appropriate for the challenges posed by climate change.

Adoption of existing and new technologies is a crucial element of mitigation of and adaptation to climate change. There is evidence that many barriers to adoption of new valuable technology exist, which are discussed in the literature (Zilberman et al. 2004). New information and communication technologies provide new opportunities to improve the ways that new technologies are introduced and marketed to enhance adoption. These technologies can be used to improve the information that farmers have of new technologies, accelerate the learning curve of using technologies efficiently and effectively, and reduce the fit and reliability risk associated with these technologies. Innovative approaches may be applied by cooperative extension as well as the private sector.

Migration Since climate change will result in relocation of people, design of mechanisms and institutions to facilitate peaceful migration and relocation will become important. As the 2015 migration crisis ${ }^{1}$, resulting from the Syrian war and other problems, in Europe suggests, accommodating immigrants is a major policy challenge. Mechanisms to address the increase in migration due to climate change will be a priority of climate smart policy. According to Docherty and Giannini (2009), there is an urgent need to develop innovative approaches to address the climate change refugee problem. They call for a new legal instrument that will establish the

\footnotetext{
${ }^{1}$ See for example: "How Climate Change is Behind the Surge of Migrants to Europe" Time Magazine, September 7, 2015.
} 
human rights of climate refugees, mechanisms for humanitarian aid, and develop criteria to share the burden of relocating climate refugees, as well as financing the relocation efforts. Because climate change will also create new agricultural opportunities, it will be ideal to develop an institutional framework that will enable farmers, especially within regions, to relocate from locations that suffer from climate change to ones that offer new opportunities. The development of institutions to address migration and relocation requires multi-disciplinary efforts and international collaboration and it is a major and urgent challenge.

\section{Overcoming Barriers to Innovation in the Era of Climate Change}

Practitioners have been a major source of innovations throughout history. For example, the wheel, crops for cultivation, and initial farming practices were identified and improved by practitioners. However, science and research are becoming major sources for new innovations in the modern era (Harari 2014). Still further, in the case of climate change, it is important to accelerate the innovative process so that new solutions will be available when and where climatic changes materialize. Scientific research has contributed to the development of new forms of engines, electric appliances, and new medicines, as well as fertilizers and new crop varieties. The innovation process goes through multiple stages. In the case of technological innovation, the process begins with research activities that lead to discoveries of ideas, which are at the core of new innovations. Then through the development process, ideas are refined, tested, and scaled up through further experimentation. For many biological and chemical innovations, the development process also includes government approval for use before commercialization. Upon product feasibility and approval, it is commercialized through activities of production and marketing. Consumers begin to adopt the product, both using and evaluating it, and their feedback leads to product refinement and further innovations. This mostly linear characterization ignores feedbacks and interactions (Etzkowitz 2010) but provides a useful framework to consider some of the major challenges faced by new innovations. In the case of managerial and institutional innovation, the innovation process may also start with research activities that identify alternative options to solve a problem, for example, through economic research or decision theory. Once solutions are identified, there will be a process of experimentation. Managerial and institutional innovations are frequently introduced gradually, for example the reforms in China were first introduced in one location and then spread gradually (Rozelle 1996). The recent increasing use of randomized controlled trials is another mechanism that exist for the introduction and diffusion of new managerial and institutional innovation.

A viable and effective research infrastructure contributes significantly to the introduction of new innovations. The theory of induced innovation suggests that the selection of research priorities is affected by the potential economic gains from 
innovation and the relative effort required to attain the desired outcome. But obtaining basic research results is not sufficient to achieve practical innovations. The stage of development in scaling up results often requires more funding than the basic research. It requires organization that has the resources necessary to carry out this process. In the developed world, the public sector is more dominant in the research stage while the private sector (start-ups and multinationals) is more dominant in product development and commercialization. Because of the significant investment associated with development, companies would not otherwise engage in it absent some assurance of economic benefit from its outcome, such as intellectual property rights. This assurance is a major reason behind technology transfer from universities and research institutions, through offices of technology transfer, to the private sector (Graff et al. 2002).

The commercialization effort and investment in establishing a supply chain, which includes manufacturing, distribution, and retail outlets, for new product distribution may be more significant than the development of the product itself (Reardon and Timmer 2012). The development of the supply chain, and its subsequent patterns of production and marketing, may vary across products and locations. The private sector will not engage in development of such supply chains without the expectation that investment will result in a positive net return of capital. The private sector is more likely to invest in innovations that are directed to the needs and wants of the developed world than the developing world. For example, the higher willingness to pay by consumers in developed countries for high quality agricultural products may lead the private sector to invest more in innovations that are targeted towards these markets. Research may lead to innovation that will reduce the cost of establishing new supply chains that facilitate a faster adaptation to climate change as part of CSA.

The above analysis suggests that several barriers exist to selecting and implementing climate smart agriculture innovations that will meet the need for growth in agriculture to meet food demand and contribute to poverty reduction in developing countries. The following section presents specific barriers organized by (i) research, (ii) refinement, and (iii) commercialization, approximating the rough order of progression of an innovation.

\subsection{Research and Refinement}

Knowledge and technology The development of production practices as well as new crop varieties that may enable adaptation to climate change require knowledge that combines understanding of crop systems, current and alternative practices, and biophysical constraints for a given location. Thus, it is important to invest both in basic research as well as applied development efforts especially because the private sector is less likely to tend to the problems of developing countries. The Consultative Group on International Agricultural Research (CGIAR) centers emphasize research on the challenges of the developing world, and national agriculture research centers 
are supposed to focus on the application of innovations to local needs. However, while this bifurcated system had significant achievements during the Green Revolution, it is unclear to what extent it can meet the challenges posed by climate change. The system was not designed to withstand larger shocks and the increased degree of uncertainty and variability that are associated with climate change. It has not emphasized climate science and building large capacity to adapt to varying conditions. While this system provides a good foundation to local research and innovation, the extra benefit from extra knowledge because the growing risk of climate change suggests that this system should be reevaluated and strengthened (Sanchez 2000).

Many of the technologies required to adapt to and mitigate climate change are developed at universities in the developed world. Developing of mechanisms to accelerate the transfer of knowledge to action in developing countries coping with climate change problems is a major challenge. But to be effective, technology transfer should include local adaptation and adjustments. Furthermore, a key challenge is to develop systems that will incorporate local and traditional knowledge in agricultural production systems. Thus, new systems will incorporate modern methods with traditional models adjusted to local conditions (Nyong et al. 2007). It requires enhancing human capital and research capacity at universities in developing countries, engaging developing mechanisms to identify local knowledge to innovation systems and providing ongoing support for collaborative research between universities.

Intellectual property rights One of the main challenges associated with transfer of information is that much of it is proprietary and thus protected by intellectual property rights. However, several mechanisms exist to address this situation. First, much of the innovation, especially in the area of biotechnology, was generated at universities that sold some of these rights to the private sector (Graff et al. 2003). However, the licensing frequently does not cover application to crops for use in developing countries. And thus, establishment of a clearinghouse would serve to facilitate the transfer of public control intellectual protection rights for use in developing countries can go a long way to solve the IPR challenge (Graff and Zilberman 2001). Indeed, some facilitating organizations for technology transfer exist, including Public-Sector Intellectual Property Resource for Agriculture (PIPRA) and African Agricultural Technology Foundation (AATF). Here should also raise the international treaty for plant genetic resources.

Fit One of the major barriers of technology is that technologies may not fit the specific needs, preferences, or capacities of the intended adopters. Much of the effort of marketing is to reduce fit risk (i.e. probability that the technology is not adopted) through demonstrations, return policies, education \& training, etc. (Zhao et al. 2012). However, lack of fit may arise from inappropriate design that does not take account of the needs and desires of the particular population. Therefore, there exists a place for participatory research and wide engagement of community in product design and introduction. This approach builds a bridge between the innovation and extension of the technology. One of the major factors of success of drip 
irrigation in some regions is that cooperative extension worked with practitioners to redesign complementary aspects of the production system so that the new irrigation system would fit with other components of the extant system. Venot et al. (2014) argue that for a technology to be successfully adopted, the production system and technology must be re-designed to incorporate the multiple contexts and practices of the specific location.

Financing The innovation process serves as an investment to produce new procedures and institutions that can help address climate change. Each stage of the innovation process requires finance, often in unique ways for research, development, production, and adoption. Because mitigation and adaptation to climate change have properties of public goods (as we argued, climate change may result in damage to public infrastructure and human life throughout the world), the finance should rely on public sources in addition to private ones. The role of public finance may be more essential in some aspects of the innovation process (e.g. basic research). But since much of the technological innovations associated with climate smart agriculture will be introduced in developing countries, development of targeted funds to facilitate adoption will be a major priority. For example, this can be accomplished through financial mechanisms ${ }^{2}$ that support innovations and adaptations to climate change in the developing world.

\subsection{Commercialization/Adoption}

Knowledge dissemination systems Dissemination of new technologies in developed countries is done jointly by the public and private sector (Wolf et al. 2001). Farmers receive information about new technologies from agricultural media, commercial vendors, cooperative extension, and commodity associations. Frequently media processes information obtained from cooperative extension. Different sources of information have varying degrees of reliability while also highlighting different aspects of some technology (Just et al. 2002). In many developing countries especially vulnerable to climate change, the knowledge dissemination system may be lacking. For example, the private sector may not invest in distribution networks, extension services may be understaffed and underfunded, and access to information from media may be limited. Frequently, the introduction of new technologies will require the development of a dissemination system. Dissemination will improve with investment in extension services and a communication network.

Limited incentives for farmers to adopt innovations Many of the innovations that are associated with CSA address problems of externalities and public goods. For example, innovations that lead to a reduction of GHG emissions provide a public good. When externalities or public goods exist, there are likely to be problems of market failure. In particular, adopters will not capture the social benefit associated

\footnotetext{
${ }^{2}$ a la the Clean Development Mechanism of the Kyoto Protocol that is well-designed.
} 
with reduction of externalities or provision of public goods. Thus, policy interventions are needed to incentivize and enhance adoption. Mechanisms suggested by environmental economists (e.g. financial incentives, direct control, subsidies, voluntary agreements) require design of policies that take into account financial and institutional arrangements (Hanley et al. 2007). The new knowledge of behavioral economics suggests the value of nudges (positive reinforcement and indirect suggestion) as a mechanism to enhance adoption and utilization of new innovations (Thaler and Sunstein 2008).

Limited incentives for governments to adopt progressive regulatory regimes Because climate change may require introduction of new varieties and new crop production systems at various locations, and changes may occur frequently over time, capacity to innovate and adopt in a timely matter will be important. One of the major barriers to introduction of new varieties is a regulatory that hinders dynamic growth. Regulations are of prime importance because much of agricultural technology may pose unforeseen risks. However, the regulatory process may be too lengthy and costly and hinder the creation of institutions that accelerate innovation, such as CSA practices. Efficient regulation should balance risks and benefits, taking account of precautionary measures, ${ }^{3}$ but also take into account the cost of not implementing a new technology. ${ }^{4}$ A regulatory system should be designed to avoid bureaucratic redundancy and to be transparent. One of the challenges of introducing a portfolio of technologies within CSA is to design and build human capital and procedures to ensure effective implementation with appropriate safety mechanisms (Rennings 2000).

The challenge of regulatory systems is in adjustment of regulation and policy to account for variability of conditions within agriculture and the heterogeneity of impact as well as the uncertainty not only with technology vis-à-vis climate change but also the need for technology to be able to adjust to diverse conditions and respond to unexpected random shocks. A flexible system of regulation would include insurance, credit, land use and property right regimes similar to those described in this chapter, thus acknowledging the challenges of implementing innovations that adequately address the impacts of climate change.

Finance The literature on adoption recognizes credit constraint as a major obstacle to adoption of new agricultural technologies, especially for the poor in developing countries who are further among the most vulnerable to the effects of climate change (Zilberman et al. 2012). Availability of credit depends on an individual's capacity to repay loans with income generated by the technology financed. When CSA does not increase significantly the expected profitability or earned income, but mostly serves to decrease risk or reduce externalities, financial constraints will be even more binding. This constraint can be relaxed through policies that provide increased availability

\footnotetext{
${ }^{3}$ For example, using a risk threshold that may occur at $1 \%$, or even lower, for risk analysis (Lichtenberg and Zilberman 1988).

${ }^{4}$ The regulatory delay on the introduction of golden rice is an example of the cost of excessive regulation of a new technology that has the potential to benefit the poor.
} 
of credit directly or by paying for environmental services associated with adoption of the technology.

Certification Innovation or adoption of strategies that will enable mitigation of or adaptation to climate change is likely to be greater if the innovators or adopters are rewarded. Economists prefer to use financial incentives to encourage environmental stewardship. But, when mandatory environmental policies are not feasible, voluntary policies may be attractive. For example, innovative environmental certification has enhanced environmental practices and tourism in Costa Rica (Rivera 2002). In the case of climate change, economists have advocated for introduction of a carbon tax because it provides incentives to reduce emissions of GHGs and enhance mitigation. However, carbon tax mechanisms in agriculture do not yet exist. An alternative mechanism to encourage adoption of climate change reducing strategies is to develop a voluntary mechanism such as certification that increases the value of products produced with practices deemed to effectively address climate change challenges.

A key component of CSA may be to identify practices that are desirable within this context and to develop a mechanism for certification that will reward policy makers that pursue such practices. While this approach has much merit, its implementation is challenging due to issues of fraud and the cost of monitoring (Hamilton and Zilberman 2006). For example, de Janvry and Sadoulet (2015) show how the implementation of a certification program, in this case Fair Trade, may not lead to the desired outcomes. Furthermore, in the case of CSA, the program may backfire if it does not correctly identify activities that contribute to effective management of climate change challenges. Therefore, the design of any certification program must be done in consultation with the latest scientific information available and the performance of the program must be reassessed periodically to ensure it takes into account new knowledge.

Unintended consequences of conservatism While environmental groups are among the most concerned about climate change, and were on the forefront of developing mechanisms to finance mitigation, sometimes they may oppose many innovative technologies and institutions that may be part of the solution to the challenges of climate change. This cautious response is not surprising because the traditional instinct of such groups is to protect and conserve (Douglas and Wildavsky 1983). Yet scientific progress may lead to new outcomes that may change reality and have uncertain outcomes. It is prudent to develop regulatory systems to pre-test new technologies, monitor and reevaluate their performance and then design regulations. But over regulation may lead to underinvestment in research that may stymie the development and implementation of new innovations. The risk of implementing new innovative concepts should be compared with the cost of not utilizing them. There are some special examples where strong objection to new innovations on environmental grounds may be especially counter productive. Changes in weather may lead to initiatives to change land use and in some cases conversion of wilderness areas to agricultural production. These initiatives should be considered and adopted if their expected benefits significantly exceed their costs. New technologies that take 
advantage of modern molecular biology, including genetic modification, should be considered as part of the solution to climate change (Zilberman 2015) These new technologies have significant potential for fast adaptation and reduced human footprint, and the resistance to such technologies can be counterproductive. ${ }^{5}$

The notion of sustainable development recognizes that dynamic processes are occurring and realities are changing. It aims to enhance human development and growth while protecting human well-being and environmental quality (Zilberman 2014). A defensive environmental strategy justifies mitigation and mechanisms to address it, such as carbon tax, but may provide obstacles to adaptation. For example, with climate change, some areas that are considered wilderness will have to be converted to agricultural use. Thus, zoning will need to be flexible to accommodate changing conditions.

\subsection{Discussion}

Barriers to innovation may vary across different categories of innovation, as well as over space and time. Scientific knowledge in the biophysical fields may be a significant barrier to cutting edge technological innovation and thus require significant investment in research. Furthermore, the knowledge gap varies across fields and different types of innovation. The knowledge gap in social sciences on understanding human behavior may hinder the development of management innovations. It can be addressed by both advanced conceptual understanding as well as experimentation with various types of management schemes under different conditions. Lack of information on behavior of both socioeconomic and biophysical systems under different conditions is another constraint on further development of innovations and especially refining it to address the specific needs of the end users. Thus improved data collection and methods can reduce these constraints. Financial constraints may be especially limiting for the development of capital intensive technological innovation but also may limit the development of managerial or institutional innovations that require investment in infrastructure. For example, the introduction of a carbon tax or incentive for carbon reduction that would lead to carbon saving practices, might require investment in monitoring to implement the policy.

Policies to reduce barriers to innovation require significant amounts of research on the institutional framework, technology transfer and adoption. This research should investigate the design of institutions that allocate research funding to

\footnotetext{
${ }^{5}$ The case of genetically modified (GM) organisms is one example. As Bennett et al. (2013) have shown, GM technologies increase yield and reduce agricultural footprint as well as having a big potential to have environmental protection and adaptation to climate change. Their further use is slowed down by objections from environmental groups. Some of the objections to adoption of GMOs are based on the fact that much of the technology was developed by private sector. Yet there are mechanisms that allow access to the technology to develop new varieties for farmers in developing countries (Graff et al. 2003).
} 
innovative activities in a fair, efficient manner that take into account both costs and benefits as well as various levels of assessed risk. The allocation of resources must have a strong spatial element capable of addressing the needs of remote areas, local communities, and have a cultural understanding to get buy-in for new solutions. Furthermore, a key element in developing policy is alliance between the private and public sector that will allow smooth technology transfer and efficient commercialization of new innovations.

\section{Conclusion}

Climate change is a dynamic process and its evolution and impacts depend on human actions. Without mitigation and with continuing build up of GHGs in the atmosphere, the severity of climate change impacts increase over time. At the early stages of climate change, adaptation may be incremental. It mostly consists of responses to changes in variability, increased mitigation efforts, better learning and understanding of climate change, development of new technologies and design of infrastructure and more transformative adaptation in anticipation of more drastic changes (Sea level rise, significant migration of weather). During these periods the challenge is in the response to crisis, mitigation, and development of capacity that may allow for adaptation to more drastic changes.

At future dates for many parts of the world, the new capacity and preparation in terms of technology and institutions in the near future will allow regional transformations of agriculture, peaceful migration and resettlement, and new reallocation and better management of water and other resources in response to more drastic changes. However, the timing for transformational adaptation varies by location. For instance, in low-lying coastal areas, such as Bangladesh, this form of adaptation may be required in the near future (Kates et al. 2012).

Adaptation to climate change does not occur in isolation, but rather in parallel with other dynamic processes. The impact of climate change, and the design of adaptation strategies, depends on these processes. Three processes are of particular mention: technological change, population growth, and consumption per capita. If technological change in agriculture is moving relatively fast and productive capacity outpaces growth in demand for agricultural products (resulting from population growth and growth in per capita demand), then adaptation to climate change will be less painful in terms of its impact on social welfare. If overall demand for agricultural production outpaces the rate of technological change in agriculture, then the attempts to adapt to climate change will be more painful and the challenges of climate smart agriculture will be exacerbated. If and where migration from rural to urban areas continues in many parts of the world and average farm size increases over time,${ }^{6}$ then climate smart agricultural strategies may be more affordable and the impact of climate change may be less harmful than when the landholding of

${ }^{6} \mathrm{As}$ the next generation of people that grew up on farms leave them for the cities. 
individual farmers declines. The overall geopolitical situation will be crucial to the ability of technology transfer and peaceful relocation programs in response to climate change. Thus a more peaceful, collaborative world is a necessary condition for the implementation of climate smart agriculture.

While climate change affects average conditions and variability at each location, the impacts of climate change are heterogeneous and uncertain. The heterogeneity suggests that some regions gain, others lose and the magnitude of the impacts vary as well. Furthermore, adaptation and the innovations that are associated with it vary by location.

Climate change will increase the value of good management and flexibility, especially in agriculture. Adaptation, including mitigation, to climate change will require a high degree of technological innovation, both in terms of physical technologies as well as institutions and policies. Thus, a key element to develop policies to adapt to climate change is investment in $\mathrm{R} \& \mathrm{D}$ as well as international collaboration. As CSA requires investments, namely some sacrifice in the present for future benefit, it requires buy-in, education, and building awareness about climate change and the gain from adaptation.

The analysis here suggests several principles to guide the introduction of innovation and develop capacity and policies to address climate change. First, pick up the low-lying fruit. Namely, identify no-regret strategies of R\&D and innovation that will address climate change and other pressing needs as well as emphasize costeffective strategies to mitigate and delay the effects of climate change. Second, invest in R\&D focused on the development of resource-conserving technologies and monitoring technologies. Third, emphasize innovations (technological, managerial and institutional) that increase the resilience of agriculture and allow it to withstand severe weather events. Fourth, take advantage of the frontier of knowledge of all types and utilize technologies that enhance human welfare and improve capacity to mitigate and adapt to climate change. Restricting the set of allowable solutions will reduce the capacity to sustain the effects of climate change. Fifth, emphasize the use of efficient mechanisms to incentivize farmers and other contributors to the agricultural sector to adopt smart agricultural practices. Sixth, emphasize adaptive management, which includes continuous monitoring, learning through experience, and adaptation of policies as you go. Seventh, distinguish between short-term emphasis on improved resilience in response to increased variability and long-term changes in spatial patterns that may include relocation of activities and people. Finally, harmonize agricultural and climate change policies that aim towards consistent outcomes.

\section{References}

Aker, Jenny C. "Rainfall shocks, markets and food crises: the effect of drought on grain markets in Niger." Center for Global Development, working paper (2012).

Barnosky, Anthony D., Elizabeth A. Hadly, Jordi Bascompte, Eric L. Berlow, James H. Brown, Mikael Fortelius, Wayne M. Getz et al. "Approaching a state shift in Earth/s biosphere." Nature 486, no. 7401 (2012): 52-58. 
Basist, Alan, Ariel Dinar, Brian Blankenspoor, and Harold Houba. "Global Land Surface Wetness and Temperature from Space, using Passive Microwave Emission: the Value of Satellite Information in Crop Yield Prediction and River Discharge Models." FAO. Forthcoming.

Bennett, Alan B., Cecilia Chi-Ham, Geoffrey Barrows, Steven Sexton, and David Zilberman. "Agricultural biotechnology: economics, environment, ethics, and the future." Annual Review of Environment and Resources 38 (2013): 249-279.

Binswanger-Mkhize, Hans P. "Is there too much hype about index-based agricultural insurance?" Journal of Development Studies 48, no. 2 (2012): 187-200.

Branca, Giacomo, Leslie Lipper, Nancy McCarthy, and Maria Christina Jolejole. "Food security, climate change, and sustainable land management. A review." Agronomy for sustainable development 33, no. 4 (2013): 635-650.

Chartzoulakis, Konstantinos, and Maria Bertaki. "Sustainable Water Management in Agriculture under Climate Change." Agriculture and Agricultural Science Procedia 4 (2015): 88-98.

De Janvry, Alain, Craig McIntosh, and Elisabeth Sadoulet. "Fair trade and free entry: can a disequilibrium market serve as a development tool?.” Review of Economics and Statistics 97, no. 3 (2015): 567-573

Dasgupta, Susmita, Benoit Laplante, Craig Meisner, David Wheeler, and Jianping Yan. "The impact of sea level rise on developing countries: a comparative analysis." Climatic change 93, no. 3-4 (2009): 379-388.

Dercon, Stefan. "Income risk, coping strategies, and safety nets." The World Bank Research Observer 17, no. 2 (2002): 141-166.

Dixit, Avinash K., and Robert S. Pindyck. Investment under uncertainty. Princeton university press, 1994.Princeton, New Jersey

Dobermann, Achim, Simon Blackmore, Simon E. Cook, and Viacheslav I. Adamchuk. "Precision farming: challenges and future directions." In Proceedings of the 4th International Crop Science Congress, vol. 26. 2004.

Docherty, Bonnie, and Tyler Giannini. "Confronting a rising tide: a proposal for a convention on climate change refugees." Harv. Envtl. L. Rev. 33 (2009): 349.

Donaldson, Dave. Railroads of the Raj: Estimating the impact of transportation infrastructure. No. w16487 National Bureau of Economic Research, 2010.

Douglas, Mary, and Aaron Wildavsky. Risk and culture: An essay on the selection of technological and environmental dangers. Univ of California Press, 1983.

Etzkowitz, Henry. The triple helix: university-industry-government innovation in action. Routledge, 2010.

Fischer, Erich M., and Christoph Schär. "Future changes in daily summer temperature variability: driving processes and role for temperature extremes." Climate Dynamics 33, no. 7-8 (2009): 917-935.

Golden, Linda L., Mulong Wang, and Chuanhou Yang. "Handling weather related risks through the financial markets: Considerations of credit risk, basis risk, and hedging." Journal of Risk and Insurance 74, no. 2 (2007): 319-346.

Graff, Gregory, and David Zilberman. "An intellectual property clearinghouse for agricultural biotechnology.” Nature Biotechnology 19, no. 12 (2001): 1179-1180.

Graff, Gregory, Amir Heiman, David Zilberman, Federico Castillo, and Douglas Parker. "Universities, technology transfer and industrial R\&D." In Economic and social issues in agricultural biotechnology Wallingford: CABI Publishing Wallingford (2002): 93-117.

Graff, Gregory D., Susan E. Cullen, Kent J. Bradford, David Zilberman, and Alan B. Bennett. "The public-private structure of intellectual property ownership in agricultural biotechnology." Nature biotechnology 21, no. 9 (2003): 989-995.

Grafton, R. Quentin, Jamie Pittock, Richard Davis, John Williams, Guobin Fu, Michele Warburton, Bradley Udall, et al. "Global insights into water resources, climate change and governance." Nature Climate Change 3, no. 4 (2013): 315-321.

Hamilton, Stephen F., and David Zilberman. "Green markets, eco-certification, and equilibrium fraud.” Journal of Environmental Economics and Management 52, no. 3 (2006): 627-644. 
Hanley, Nick, Jason F. Shogren, and Ben White. Environmental economics: in theory and practice. New York: Palgrave macmillan, 2007.

Harari, Yuval Noah.: Sapiens: A brief history of Humankind Random House, New York 2014.

IPCC "Climate Change 2014: Impacts, Adaptation and Vulnerability, summary for Policymakers" WGII Contriubtion ot the Fifith assessment report of the IPCC, WHO, UNEP.

Just, David R., Steven A. Wolf, Steve Wu, and David Zilberman. "Consumption of economic information in agriculture." American Journal of Agricultural Economics 84, no. 1 (2002): 39-52.

Kates, Robert W., William R. Travis, and Thomas J. Wilbanks. "Transformational adaptation when incremental adaptations to climate change are insufficient." Proceedings of the National Academy of Sciences 109, no. 19 (2012): 7156-7161.

Khanna, Madhu, and David Zilberman. "Incentives, precision technology and environmental protection.” Ecological Economics 23, no. 1 (1997): 25-43.

Krueger, Anne O. Government failures in development. No. w3340. National Bureau of Economic Research, 1990.

Kurukulasuriya, Pradeep, and Shane Rosenthal. "Climate change and agriculture: A review of impacts and adaptations." (2013).

Lal, Rattan. "Sequestering carbon in soils of agro-ecosystems." Food Policy 36 (2011): S33-S39.

Lenton, Timothy M., Hermann Held, Elmar Kriegler, Jim W. Hall, Wolfgang Lucht, Stefan Rahmstorf, and Hans Joachim Schellnhuber. "Tipping elements in the Earth's climate system." Proceedings of the National Academy of Sciences 105, no. 6 (2008): 1786-1793.

Lichtenberg, Erik, and David Zilberman. "Efficient regulation of environmental health risks." The Quarterly Journal of Economics (1988): 167-178.

Lu, Liang, Thomas Reardon, and David Zilberman. "Supply Chain Design and Adoption of Indivisible Technology." Presentation at Allied Social Sciences Association Annual Meeting (2015).

McCarthy, N., L. Lipper, W. Mann, G. Branca, and J. Capaldo. "Evaluating synergies and tradeoffs among food security, development and climate change." Climate Change Mitigation and Agriculture (2012): 39-49.

McGranahan, Gordon, Deborah Balk, and Bridget Anderson. "The rising tide: assessing the risks of climate change and human settlements in low elevation coastal zones." Environment and urbanization 19, no. 1 (2007): 17-37.

Mendelsohn, Robert. "The role of markets and governments in helping society adapt to a changing climate." Climatic change 78, no. 1 (2006): 203-215.

Millner, Antony, Simon Dietz, and Geoffrey Heal. Ambiguity and climate policy. No. w16050. National Bureau of Economic Research, 2010.

Moschini, Giancarlo, and David A. Hennessy. "Uncertainty, risk aversion, and risk management for agricultural producers." Handbook of agricultural economics 1 (2001): 88-153.

Nelson, Richard R., ed. National innovation systems: a comparative analysis. Oxford university press, 1993.

Nyong, Anthony, Francis Adesina, and B. Osman Elasha. "The value of indigenous knowledge in climate change mitigation and adaptation strategies in the African Sahel." Mitigation and Adaptation Strategies for Global Change 12, no. 5 (2007): 787-797.

Ohmura, Atsumu. "Enhanced temperature variability in high-altitude climate change." Theoretical and Applied Climatology 110, no. 4 (2012): 499-508.

Parfitt, Julian, Mark Barthel, and Sarah Macnaughton. "Food waste within food supply chains: quantification and potential for change to 2050." Philosophical Transactions of the Royal Society of London B: Biological Sciences 365, no. 1554 (2010): 3065-3081.

Parker, Douglas D., and David Zilberman. "The use of information services: The case of CIMIS." Agribusiness 12, no. 3 (1996): 209-218.

Patt, Anthony, Nicole Peterson, Michael Carter, Maria Velez, Ulrich Hess, and Pablo Suarez. "Making index insurance attractive to farmers." Mitigation and Adaptation Strategies for Global Change 14, no. 8 (2009): 737-753.

Porter, J. H., M. L. Parry, and T. R. Carter. "The potential effects of climatic change on agricultural insect pests." Agricultural and Forest Meteorology 57, no. 1 (1991): 221-240. 
Poteete, Amy R., Marco A. Janssen, and Elinor Ostrom. Working together: collective action, the commons, and multiple methods in practice. Princeton University Press, Princeton, New Jersey 2010

Reardon, Thomas, and C. Peter Timmer. "The economics of the food system revolution." Annu. Rev. Resour. Econ. 4, no. 1 (2012): 225-264.

Rennings, Klaus. "Redefining innovation-eco-innovation research and the contribution from ecological economics." Ecological economics 32, no. 2 (2000): 319-332.

Rivera, Jorge. "Assessing a voluntary environmental initiative in the developing world: The Costa Rican Certification for Sustainable Tourism." Policy Sciences 35, no. 4 (2002): 333-360.

Rozelle, Scott. "Gradual reform and institutional development: The keys to success of China's agricultural reforms." Reforming Asian Socialism. The Growth of Market Institutions (1996): 197-220.

Sandmo, Agnar. "On the theory of the competitive firm under price uncertainty." The American Economic Review 61, no. 1 (1971): 65-73.

Sanchez, Pedro A. "Linking climate change research with food security and poverty reduction in the tropics." Agriculture, Ecosystems \& Environment 82, no. 1 (2000): 371-383.

Schmitz, Andrew. Agricultural policy, agribusiness, and rent-seeking behavior. University of Toronto Press, Toronto 2010.

Schoengold, Karina, and David Zilberman. "The economics of water, irrigation, and development." Handbook of agricultural economics 3 (2007): 2933-2977.

Smith, Vincent H. and Barry K. Goodwin. "The Environmental Consequences of Subsidized Risk Management and Disaster Assistance Programs." Annual Review of Resource Economics vol. 5 (2013): 35.60.

Stern, Nicholas Herbert. The economics of climate change: the Stern Review. Vol. 30. London: HM treasury, 2006.

Sunding, David, and David Zilberman. "The agricultural innovation process: research and technology adoption in a changing agricultural sector." Handbook of agricultural economics 1 (2001): 207-261.

Thaler, Richard H. and Sunstein, CR "Nudge: Improving decisions about health, wealth, and happiness." Yale University Press Connecticut, New Haven (2008).

Tol, Richard SJ. "The economic effects of climate change." The Journal of Economic Perspectives (2009): 29-51.

Venot, Jean-Philippe, Margreet Zwarteveen, Marcel Kuper, Harm Boesveld, Lisa Bossenbroek, Saskia Van Der Kooij, Jonas Wanvoeke et al. "Beyond the promises of technology: A review of the discourses and actors who make drip irrigation." Irrigation and drainage 63, no. 2 (2014): 186-194.

Waterfield, Gina, and David Zilberman. "Pest management in food systems: An economic perspective." Annual Review of Environment and Resources 37 (2012): 223-245.

Weitzman, Martin L. "On modeling and interpreting the economics of catastrophic climate change." The Review of Economics and Statistics 91, no. 1 (2009): 1-19.

Wesseler, Justus, and David Zilberman. "The economic power of the Golden Rice opposition." Environment and Development Economics 19, no. 06 (2014): 724-742.

Williams, Jeffrey C., and Brian D. Wright. Storage and commodity markets. Cambridge university press, Cambridge 2005.

Wolf, Steven, David Just, and David Zilberman. "Between data and decisions: the organization of agricultural economic information systems." Research policy 30, no. 1 (2001): 121-141.

Xie, Yang, David Zilberman, and David Roland-Holst. "Implications of Climate Change for Adaptations through Water Infrastructure and Conservation" (2015).

Xie, Yang, and David Zilberman. "Theoretical implications of institutional, environmental, and technological changes for capacity choices of water projects." Water Resources and Economics 13, no. 4 (2016): 19-29.

Zilberman, David. "IPCC AR5 overlooked the potential of unleashing agricultural biotechnology to combat climate change and poverty." Global change biology 21, no. 2 (2015): 501-503. 
Zilberman, David, Xuemei Liu, David Roland-Holst, and David Sunding. "The economics of climate change in agriculture." Mitigation and Adaptation Strategies for Global Change 9, no. 4 (2004): 365-382.

Zilberman, David, Jinhua Zhao, and Amir Heiman. "Adoption versus adaptation, with emphasis on climate change." Annu. Rev. Resour. Econ. 4, no. 1 (2012): 27-53.

Zilberman, David. "The economics of sustainable development." American Journal of Agricultural Economics 96, no. 2 (2014): 385-396.

Open Access This chapter is distributed under the terms of the Creative Commons AttributionNonCommercial-ShareAlike 3.0 IGO license (https://creativecommons.org/licenses/by-nc-sa/3.0/ igo/), which permits any noncommercial use, duplication, adaptation, distribution, and reproduction in any medium or format, as long as you give appropriate credit to the Food and Agriculture Organization of the United Nations (FAO), provide a link to the Creative Commons license and indicate if changes were made. If you remix, transform, or build upon this book or a part thereof, you must distribute your contributions under the same license as the original. Any dispute related to the use of the works of the FAO that cannot be settled amicably shall be submitted to arbitration pursuant to the UNCITRAL rules. The use of the FAO's name for any purpose other than for attribution, and the use of the FAO's logo, shall be subject to a separate written license agreement between the FAO and the user and is not authorized as part of this CC-IGO license. Note that the link provided above includes additional terms and conditions of the license.

The images or other third party material in this chapter are included in the chapter's Creative Commons license, unless indicated otherwise in a credit line to the material. If material is not included in the chapter's Creative Commons license and your intended use is not permitted by statutory regulation or exceeds the permitted use, you will need to obtain permission directly from the copyright holder.

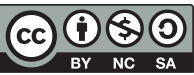

